\title{
Socio-demographic and clinical characteristics of adults under involuntary hospitalization in the acute mental health services of Cyprus
}

Katerina G. Kaikoushi ( $\sim$ katerina.ksh@gmail.com )

Cyprus Mental Health Services

\section{Bella Evanthia}

Cyprus Mental Health Services

\section{Middleton Nicos}

Cyprus University of Technology Faculty of Health Sciences

\section{Chatzitofis Andreas}

University of Cyprus

Alevizopoulos George

National and Kapodistrian University of Athens

\section{Stylianou Constantinos}

Cyprus Mental Health Services

\section{Kinnis Evgenios}

Cyprus Mental Health Services

\section{Karanikola Maria}

Cyprus University of Technology Faculty of Health Sciences

\section{Research article}

Keywords: demographic characteristics, compulsory hospitalization, involuntary admission, mental illness, neurobiological disorders

Posted Date: December 12th, 2019

DOl: https://doi.org/10.21203/rs.2.18633/v1

License: (c) (i) This work is licensed under a Creative Commons Attribution 4.0 International License. Read Full License 


\section{Abstract}

Background: The clinical and demographic characteristics of the adults involuntary admitted for compulsory mental health treatment have not been reported adequately. Purpose: Investigation of the socio-demographic and clinical characteristics of the adults who are involuntary hospitalized in the acute Mental Health Services in Cyprus.

Method: A descriptive correlation study with cross-sectional comparisons was applied. Data collection was performed from December 2016 to February 2018 via a structured questionnaire including demographic and clinical variables. Each questionnaire was accompanied by a consent form, which was assigned by the participants before their discharge.

Results: The sample consisted of 406 people, of whom 262 were male and 144 were female. The vast majority were Greek-Cypriots. The largest age groups were $45-65$ years (33\%) and 25-34 years (31.8\%), respectively. 172 of the participants reported current substance use and 117 of them fulfilled the criteria of dual diagnosis. The most frequent diagnosis was schizophrenia or a relevant psychotic disorder (86.4\%). The main cause of relapse and subsequent admission was medication non-adherence along with lack of insight (57.1\%). 52\% of the sample had been previously involuntary hospitalized in a psychiatric hospital.

Conclusions: A high percentage of involuntary hospitalizations was noted due to non-adherence to pharmacotherapy. Re-evaluation of the effectiveness of relevant community interventions is suggested, as well as implementation of structured educational programs on therapy adherence during hospitalization. The goal is the limitation of the frequency of relapse while being in the community. Also, education on substance use prevention is also suggested for clinical populations. Keywords: demographic characteristics, compulsory hospitalization, involuntary admission, mental illness, neurobiological disorders

\section{Introduction}

Although there is longstanding evidence showing that the incidence of mental disorders in the general population is increasing globally ${ }^{1}$, data on the factors triggering severe mental health disturbances leading to compulsory treatment have not been addressed adequately ${ }^{2}$. Involuntary or compulsory treatment is a procedure mainly applied to people with mental disorders lacking their consent, when the intensity of the symptomatology is severe enough to jeopardize personal or social interest ${ }^{3}$.

Data on the effectiveness of compulsory treatment are insufficient ${ }^{4-5}$ while self-stigma in those involuntary hospitalized for compulsory mental health treatment has been well described in the international literature ${ }^{6}$. At the same time, compulsory hospitalization has been described as a severe stressor for family members of those involuntary admitted to psychiatric units for compulsory treatment, as well as for the healthcare professionals providing care to them ${ }^{7}$. Thus, documentation of data which 
may be applied in policy-making to prevent compulsory hospitalization in people facing mental health problems may be an important public health issue.

At the same time, the socio-demographic and clinical characteristics of the individuals under compulsory mental health treatment orders have not been reported adequately in the international context ${ }^{8-9}$. Yet, identification of possible clinical and demographic risk factors for severe relapse leading to involuntary hospitalization may be relevant in formulating targeted interventions to empower clinical population and prevent relapse during their staying in the community ${ }^{10}$. Overall, reports on the risk profile of those involuntary hospitalized in mental health units may support relevant interventions regarding treatment options, education and follow up modifications ${ }^{11-12}$.

\section{The context of Cyprus}

According to the Psychiatric Compulsory Hospitalization Act of the Republic of Cyprus involuntary hospitalization is deemed as the case of one's admission in a special psychiatric unit for treatment and care following a judicial decree instead of the patient's consent [on Psychiatric Hospitalization Act of 1997 (77 (I)/1997) $]^{13}$. Under this scope, for an involuntary hospitalization to take place all the following three criteria need to be fulfilled: (a) diagnosis of a mental disorder, (b) incapacity of judgment in the interest of one's own health, (c) receiving no treatment may severely affect a patient's safety or recovery. Additionally, involuntary hospitalization is also applied to individuals diagnosed with a mental disorder in order to prevent acts of violence against themselves or others. According to the present legislation in the Republic of Cyprus, involuntary hospitalization under a judicial decree is provided only in high security units within psychiatric hospitals, while the duration of involuntary hospitalization is 28 days $^{13}$.

Previous data by the Ministry of Health of Cyprus have shown an upward trend of involuntary admissions in the acute mental health services per year since 2007, without, however, mentioning the demographics of this group of service users ${ }^{14}$. Furthermore, a literature review in the databases Pubmed, GoogleScholar, Medline, Embase, and Psyclnfo, to the best of our knowledge, did not reveal any epidemiological study in people who are involuntary admitted for compulsory treatment in the acute mental health services in Cyprus $^{15-17}$, while relevant data from international contexts are also scare ${ }^{18-19}$. Therefore, it would be useful to report on the clinical characteristics and demographics of those involuntary hospitalized in acute mental health services in the cultural context of Cyprus; such data will form a national base on the one hand, but will also allow future comparisons with international data, on the other ${ }^{9}$. Also, such data may inform policy-making nationally and internationally.

\section{Aim}

The aim of the present study was the investigation of the socio-demographic and clinical characteristics of the adults who were involuntary hospitalized under compulsory mental health treatment order. 


\section{Material And Method \\ Research design}

A descriptive correlational study with cross-sectional comparisons was applied.

\section{Study environment}

The study environment was the Athalassa Psychiatric Hospital (APH). APH is the only inpatient unit of the mental health services of Cyprus where compulsory mental health treatment orders are executed. The capacity of the APH is 132 beds distributed to one admission unit for males (19 beds), one admission unit for females ( 19 beds), a high safety nursing ward ( 2 beds) and three rehabilitation wards covering a population of approximately 1,000,000 individuals representing the Greek speaking part of Cyprus. According to the most recent annual report of the Cyprus Ministry of Health (2010), 395 individuals are involuntary hospitalized per year in the $\mathrm{APH}^{14}$.

\section{Target population}

The target population of the study were all the adults who were involuntary hospitalized in the APH under compulsory mental health treatment order with symptoms of psychosis, depression, mania or anxiety.

\section{Sampling method}

A census sampling method was applied for data collection from December 2016 to February 2018. All clinical and demographic data of the adults involuntary admitted to the APH during this period were assessed. The selection of the sample was made from Monday to Sunday. The days and times of data selection were randomly selected.

\section{Entry/Exclusion criteria}

The study participants had to be adults who were involuntary admitted to the APH with psychotic, mood or substance use-induced symptoms, and further diagnosed with schizophrenia spectrum and other psychotic disorders (e.g., Schizophrenia, Brief psychotic disorder, Schizoaffective disorder, Delusional disorder, Schizophreniform disorder, etc), Bipolar and related disorders, depressive disorders, Substance/medication-induced psychotic and related disorder, Substance/medication-induced bipolar and related disorder, substance/medication -induced depressive disorder. Additionally, the following inclusion criteria were applied: (a) age: 18 to 60 years; (b) comprehension of the objectives and procedures of the study; (c) written consent after information for participation in the study; (d) advanced 
knowledge of the Greek or English language, or available translator to provide relevant services to the foreigners.

Individuals with neuro-cognitive disorders, such as Alzheimer disease or delirium, mental retardation and developmental disorders were excluded.

\section{Sample size}

In total 761 admissions were recorded in the APH. 195 cases were rejected because they did not meet the age ( $n=9$ were younger than 18 years and $n=13$ were older than 65$)$ and diagnosis criteria. The later were mainly diagnosed with personality disorders $(n=152) .21$ individuals were diagnosed with mental retardation. Moreover, 79 people were not included since informed consent was not achieved, either because the level of insight was not adequate at the time of discharge from the APH $(n=43)$, or because the researcher was not present during the discharge, thus did not have the chance to have a meeting with the patient regarding informed consent process $(n=34)$. Two individuals passed away during their hospitalization. 81 over the 487 total cases of individuals meeting the inclusion criteria were repeatedly evaluated. This was due to repeated relapses during the study period. Therefore, these patients were only once included in the present sample. Thus, the final sample consisted of 406 individuals as depicted in the flowchart (Diagram 1).

\section{Data collection Process}

The primary researcher who is an advanced psychiatric-mental health nurses along and independently with the psychiatrist on duty assessed all individuals admitted in the APH who met the criteria for entry in the study. Also, the demographic and clinical data were recorded. The process of obtaining written informed consent was taking place at the day of patients' discharge from the hospital. At first the degree of insight was assessed by the primary researcher in collaboration with the psychiatrist on duty according to the degree of patients' awareness on (a) the severity of their illness, (b) the occurrence of relapse, (c) the importance of adherence to therapy via a semi-structured interview guide. In cases that the degree of insight was assessed as adequate the primary researcher was explaining the aim and the objectives of the study, confidentiality issues as well as the fact the participation was voluntary and irrelevant to the clinical outcome or therapy issues of their ill health. The assessment interview time was about 15-20 minutes, while the informed consent process lasted for approximately 25 minutes. A translator was hired to support the assessment process in $4.3 \%$ of the participants, since their mother language was neither Greek nor English.

\section{Data Collection Tool}


A structured questionnaire encompassing clinical and demographic characteristics was used for data collection. The following variables were included: Gender, age, race, nationality, mother language, place of residence, marital status, nationality/nationality of spouse, educational level, occupational status, receiving allowance, $\mathrm{BMI}$, family history of mental illness, admission diagnosis, symptom of admission and history of substance use (type and frequency). Data on substance use regarded both past and current use, with an emphasis on the period just before the onset of relapse symptoms. Regarding relapse symptoms, the most prominent according to the medical note was considered for data analysis.

\section{Ethical and ethical issues of research}

The study was approved by the National Committee of Bioethics of Cypris (EEBK/EP/2014/08), the Research Committee of the Ministry of Health of the Republic of Cyprus (PN: 5.34:01.7.3E), as well the Personal Data Protection Officer (5.43.01.7.6 E, PN: 0237 / 2014).

Following comprehensive description of the study aim and objectives the participants provided written informed consent to be included in the study. The voluntary nature of participation, the safety and anonymity of the participants as well as data confidentiality were assured. Also, the participants were informed orally and in writing through the consent form for their right to express complaints regarding the objectives and procedures of the study. All the researchers involved in the study were registered mental health professionals, and therefore legally obliged to respect data confidentiality and patient safety.

\section{Data analysis}

All variables were tested for normality and parametric/non-parametric tests were applied accordingly. Means and standard deviations (SD) were assessed for continuous variables and frequencies for categorical variable. Comparisons were assessed through the student's t or Mann Whitney U test and analysis of variance (ANOVA), as appropriate. Pearson's $r$ ( $r$ ) correlation coefficients were also explored. To explore variables potentially mediating significant associations step-wise regression analysis was applied. A nominal significance level $\mathrm{a}=0.05$ was used. Data were analyzed through the Statistical Package for Social Sciences (SPSS, Inc, Chicago, IL version 20.00).

\section{Results}

\section{Sample characteristics}

The sample included 406 individuals (262 male, 144 female), while the majority were Greek-Cypriots (72.4\%). Most of the admissions occurred in the winter (32\%) and summer $(29.3 \%)$ time, yet no statistically significant difference was noted. Most of the participants were Greek-speaking (82\%). The most frequent city of participants' residence was the Nicosia district (38.4\%). Approximately $86 \%$ of the participants were single. 
Nearly $25 \%$ of the respondents were holders of a bachelor's degree, while $39.9 \%$ had completed secondary education. Yet, most of the participants were unemployed $(n=315)$ and only half of them were receiving state financial allowance (49.5\%). The largest percentage of the participants (81.3\%) declared "Christian Orthodox".

The largest proportion of the participants belonged to the age group of $45-65$ years (33\%) and 25-34 years (31.8\%), while $13 \%$ aged between $18-24$ years. Almost one over four participants $(25.6 \%)$ was overweight $\left(\mathrm{BMI}=25-35 \mathrm{~kg} / \mathrm{m}^{2}\right)$.

172 of the participants confirmed substance use (current or previous use), while 82 of them reported more than one substance used and almost half of them reported daily substance use (52.3\%). Moreover, 117 of those who reported substance use fulfilled dual diagnosis criteria. In all cases, the most prominent substance used was cannabis (75.6\%). (Table 2 ).

The most common clinical diagnosis in the sample $(n=406)$ was schizophrenia or a relevant psychotic disorder (86.4\%).

The most frequent admission cause was non adherence to pharmacotherapy along with lack of insight (57.1\%). In particular, 34.7\% manifested disorganized behaviour and/or agitation, and/or self-care deficit along with non-adherence to pharmacotherapy and lack of insight; $19 \%$ reported aggressive behaviour towards others along with non-adherence to pharmacotherapy and lack of insight; and 3.4\% expressed suicidal behaviour along with non-adherence to pharmacotherapy and lack of insight.

The second most prominent cause of involuntary admission (23.4\%) was lack of insight along with disorganized behaviour, and/or agitation and/or self-care deficit although the participants reported adherence to pharmacotherapy in this subgroup. $9.6 \%$ were admitted due to aggressive behaviour against others and lack of insight, while $8.4 \%$ because of substance use and lack of insight. $1.5 \%$ were hospitalized because of self-harming bahaviour along with lack of insight.

Almost half of the participants (52\%) were previously involuntary hospitalized in the APH, while 195 participants were compulsory admitted there for the first time. Overall, 70.9\% $(n=288)$ had a positive history of mental health problems and 118 participants (29\%) reported that the current episode was the first diagnosed mental health disturbance. Moreover, 171 participants reported a positive family history of mental health disorders. The most frequent diagnosis in these cases was schizophrenia/relevant psychotic disorder $(18.0 \%)$ or a mood disorder $(12.8 \%)$.

\section{Differences between groups based on demographic characteristics}

With regard to positive family history of mental health illness, female $(p<0.0001)$ and white race participants $(p=0.03)$ reported more frequently a positive family history of a severe mental disorder. 


\section{Substance use and demographics}

A statistically significant association was observed between substance use and gender, since males reported more frequently substance use than females $\left(x^{2}, p<0.0001\right)$.

Also, a statistically significant association was observed between age and substance use $(p<0.0001)$, since participants aged 25-34 years reported more frequently (current or previous) substance use compared to other age groups.

The participants with a negative history of substance use seemed to report more frequently a negative history of a serious mental disorder $(p=0.007)$. Therefore, it appeared that those involuntary admitted for compulsory therapy who did not use substances were less likely to report previous severe mental health problems. A statistically significant association was observed between substance use, on the one hand, and level of education and professional status, on the other. In particular, the graduates of secondary education $(p=0.019)$ and unemployed $(p=0.019)$ were more likely to have a positive history of current or previous substance use. Also, a statistically significant association was noted between frequency of use and number of substances used, since the participants who informed substance use daily reported more frequently more than one substance used $(p<0.0001)$. Furthermore, dual diagnosis was established more frequently in males $(p<0.0001)$, in the age group of $25-34$ years $(p<0.0001)$, as well as in those reporting daily substance use $(p=0.01)$.

The subgroup of cannabis users. Cannabis was the most frequently substance used in the age group of 25-34 years, compared to other age groups $(p<0,0001)$. In addition, participants with a diagnosis of schizophrenia or other related psychotic disorders were reporting a positive history of cannabis use more frequently than participants diagnosed with other clinical conditions $(p=0.001)$. A statistically significant association was noted between district of residence and cannabis use, since the participants who resided in the Nicosia, the capital city of Cyprus, reported more often a positive history of cannabis use compared to the residents of the other urban or rural areas of Cyprus $(p=0.04)$. The unmarried participants appeared to use more frequently cannabis than married ones $(p=0.05)$. Overall, cannabis was used on a daily basis more frequently than other substances by the participants $(p=0.001)$.

\section{Symptoms during involuntary admission and demographics}

A statistically significant association was observed between admission symptoms and demographics. In particular it appeared that non-adherence to pharmacotherapy and lack of insight were more frequently manifested in the age group of $45-65$ years $(p<0.0001)$, in males $(p<0.0001)$, in white $(p<0.0001)$, in those receiving financial allowance $(p=0.029)$, with a negative history of substance use $(p<0.0001)$ and normal BMI $(p<0.0001)$, as well as in the participants diagnosed with schizophrenia or other related psychotic disorder $(p<0.001)$ and a positive history of severe mental illness $(p<0.0001)$. 


\section{Admission diagnoses and demographics}

A statistically significant association was observed between the admission diagnosis and the demographic factors. Specifically, males $(p<0.0001)$, singles $(p=0.05)$, those reporting substance use on a daily basis $(p=0.002)$, as well as those with a positive family history of severe mental illness $(P=0.001)$ and mainly of schizophrenia $(p=0,003)$ more often fulfilled the criteria for schizophrenia or other related psychotic disorder.

The participants with a positive history of substance use $(p<0,0001)$, as well as those who reported more than one substance used $(p<0,0001)$ more frequently met the criteria of a mood disorder.

\section{Discussion}

This study presents for the first time the clinical and socio-demographic characteristics of those involuntary admitted for compulsory treatment in Cyprus. These data are the first to be recorded at a national level, while international studies on the subject are relatively scarce. Yet, comprehension of the factors related to acute symptomatology of severe mental disorders is a major public health issue as well as of paramount importance for clinical practice ${ }^{20-21}$.

According to the present results, it is more likely single, unemployed males aged 45-65 years, GreekCypriots and Christians Orthodox, who reside in Nicosia district and are graduates of secondary education to be involuntary hospitalized for compulsory treatment in Cyprus. Additional risk factors found herein were schizophrenia diagnosis or a related psychotic disorder diagnosis, as well as a positive personal history of mental health problems, a positive family history of mental illness, mainly schizophrenia or other related psychotic disorder and a positive personal history of substance use.

Indeed, approximately one out of 2 participants herein reported a positive history of substance use, although most of them clarified that this regarded substance use in the past - not at present. Also, from those who reported a positive history of substance use approximately one out of two manifested daily use, while the main substance used was cannabis. Nevertheless, data show that substances use is an important clinical factor related to occurrence, as well as recurrence of mental disturbance symptoms ${ }^{22}$. In the present study almost one out of two participants reported substance use just before the onset of symptomatology that led to the involuntary hospitalization, while the main substance used was cannabis. Also, many of the participants although they did not report substance use directly before symptoms escalation or in a relatively short period prior to it, they reported a positive history of substance use in the past.

Regarding substance use occurrence in Cyprus, the study by Mitsis ${ }^{23}$ held in 100 individuals with substance use-related disorders who asked for help in a non-security, private clinic program in Cyprus, showed that cannabis was one of the most common substances used, while the majority of the participants had dual diagnosis ${ }^{23}$. Overall, although there are several studies that have investigated the 
relationship between substance use and manifestation of mental health symptoms ${ }^{24-25}$, further investigation into the relationship between substance use and involuntary hospitalization for compulsory treatment is suggested, considering the multifactorial relationship between these two phenomena and inherent difficulties ${ }^{26}$. In any case, the present study outlines for the first time in Cyprus substance use as a risk factor for involuntary hospitalization in clinical populations, providing the basis for targeted education and substance use- related preventive interventions via community settings for those with mental health problems.

An additional important finding herein regards readmission rate. In particular, $52 \%$ of the participants reported a positive history of involuntary admissions for compulsory treatment, while approximately one out of 7 of those who fulfilled the criteria of the present study had been involuntary hospitalized for more than one times in the previous 14 months. Although high, this rate seems to be relatively lower than the one reported in international literature. Other researchers report that approximately $20-40 \%$ of mental health service users are repeatedly involuntary hospitalized for compulsory treatment ${ }^{27-31}$. Frequent, repetitive involuntary hospitalization seems to be an important clinical problem in Cyprus, as well as internationally, since it seems that a large proportion of mental health service users fail to remain in remission for a long time. This underlines the need for more effective relapse preventive interventions, mainly in community level. Special focus needs to be given in the sub-group of individuals with psychotic symptoms, and mainly schizophrenia and relevant psychotic disorders. Overall, the present study confirmed previous data which show that those with schizophrenia and relevant psychotic disorders are more often involuntary hospitalized ${ }^{27-38}$.

Furthermore, additional emphasis needs to be given on educational programmes in pharmacotherapy and treatment options in order to enhance adherence to therapy, since the main cause of relapse herein as well as internationally seems to be non-adherence to pharmacotherapy $27-31,39-40$.

As for other risk factors for involuntary admission and subsequent compulsory treatment, male gender has been well documented in international literature $3,28-29,32-38,41-48,50-51$. Yet, other studies present data which report increased frequency of compulsory treatment among females 9,30,52-53,55. These data mainly come from non-European countries, i.e. USA, Croatia, China and Brazil. Regarding the APH of Cyprus, although there is equal number of beds for males and females at the acute units for compulsory treatment, most of the times the capacity in males' units is full while there are non-occupied beds in females' units (anecdotal data).

Marital status was also identified herein as a risk factor, since singles were more likely to be involuntary admitted at the APH. Indeed, international literature poses singles with no supportive family or social network in increased risk for compulsory treatment ${ }^{3,9,29-30,33,35-36,41-43,46-47,52-53,56}$. However, in one study in Bangladesh the majority of those under compulsory treatment (53.1\%) were married ${ }^{48}$.

Most of the participants herein had completed secondary education. Also, one out of 4 participants had completed tertiary education. That may suggest that despite severe mental illness the participants were 
able to proceed with their studies. On this basis, it could be considered that, compared to the past or other countries, the diagnosis of severe mental disorder in Cyprus is taking place at an early stage, and subsequently effective treatment is applied, thus restraining possible cognitive implications of severe mental disorders ${ }^{47-48}$.

The relationship between education level and involuntary admission and/or readmission for compulsory treatment reported herein is also confirmed by other studies ${ }^{27}$. Previous data show an increased incidence of admissions in high security units for compulsory treatment in those with post-graduate education, and in particular holders of diplomas in vocational specializations $3,29,30,43,45,52,56$. This may suggest that in some countries the majority of mental health service users are integrated into professional specialization programmes, which enables them to acquire vocational skills and further prevent occupational exclusion, social isolation and self-stigmatisation ${ }^{58}$. In the present study most of the participants who had completed secondary education had no such training. Therefore, more extensive and inclusive vocational specialization/post-graduate education programmes are proposed, in terms of the number of trainees and type of specialization provided to individuals with severe mental health problems. Participation in these programmes needs to start during hospitalization and be further endured after discharged and during being in the community. Similarly, a cohort study in the general population in Iran suggests that most of the mental health service uses hold a Bachelor's degree ${ }^{57}$.

Nevertheless, there are contradictory data in studies conducted in South Asia (Bangladesh), Italy, Turkey, China, Germany, Norway and Greece according to which the largest percentage of those involuntary admitted for compulsory treatment had only primary education ${ }^{41-42,47-48,51,53}$. Overall, education in professional skills and the necessity for effective vocational rehabilitation programmes needs to be a priority for healthcare systems, since there are data which show that unemployment is a severe stressor in people with mental health problems. Indeed, unemployed with financial problems seem to be more frequently involuntary admitted for compulsory treatment $3,9,27-28,30,33,36,48,56$. In contrary, there are two studies, one in Brazil and one in Cline, which show that the majority of those involuntary admitted for compulsory treatment were employed females ${ }^{52-53}$. This may be in accordance with data which show that females are twice more likely develop mental health problems ${ }^{54}$, however further investigation into culturally specific, gender-related factors associated with these data are needed.

Regarding the age of those more frequently involuntary admitted for compulsory treatment in high security units, international data show an age range between 18 to 57 years, with a mean value approximately 45 years $3,9,27,28,30-35,41-42,45-46,50-51,53,56,60$. In the present study the majority of the participants were in the age group of 45 to 65 years, while other studies provide a range closer to 45 years $^{29,37,43-44,47-48}$. At the same time, there studies which support an age range between 20 to 29 years for those more frequently involuntary admitted for compulsory treatment, while the age group 4150 years to include those less frequently involuntary hospitalized ${ }^{30,48}$. This may indicate a late diagnosis of severe mental health problems which may lead to critical escalation of the severity of symptoms thus leading the young to be more frequently involuntary hospitalized. At the same time, these findings may 
highlight the effectiveness of community therapeutic programmes in the older and subsequently limited relapse rates and need for compulsory treatment in this group of patients. It is important to note that in the studies in which there was no age limit in the inclusion criteria the researchers reported older age groups as a risk factor for compulsory treatment $27,31,52,55,60$. This may explain to some degree relevant differences with other studies.

The place of residence and origin was found as a risk factor for compulsory treatment herein. Though, international data in general population regarding residence area as a risk factor for severe mental health problems seem to be contradictory. Specifically, Dreger et al. ${ }^{59}$, described an increased prevalence of severe mental disorders in people from urban areas in relation to those from rural areas ${ }^{59}$. On the contrary, based on the results of Amoran et al. ${ }^{49}$, the largest proportion of people with severe mental health problems come from rural areas.

Regarding the link between physical characteristics and mental health problems, researchers have described the relationship between the morphology and the characteristics of the iris of the eye and the presence of symptoms of mental disorder ${ }^{61-62}$. In fact, data show a positive link between light-coloured eyes and schizophrenia, suggesting possible common genomic sites ${ }^{63-65}$. However, these data were not confirmed in the present study as no relationship was found between the type of symptoms/diagnosis and eye color.

\section{Proposed interventions}

Development of clinical guidelines regarding preventive interventions in community settings for substance use and non-adherence to therapy in clinical populations are proposed.

Additionally, reformation of the present legislation on compulsory hospitalization in Cyprus is also proposed, aiming to restrict the causes of involuntary hospitalization and, further integrate mandatory monitoring in community settings by mental health professionals. This reformation is proposed for those individuals who are in relapse or in acute phase and because of lack of or decreased insight involvement in treatment is difficult, and at the same time their behavior is not directly harmful to themselves or others. Such reforms in the legislation on compulsory treatment have been established in Portugal and Australia, followed by a reduction in the cases of involuntary hospitalization in high security psychiatric units $^{66-68}$.

Regarding educational programs on adherence to therapy, both pharmacotherapy and psycho-social interventions, special emphasis is proposed both during hospitalization and at community. A core element of these programs needs to be empowerment for participation in clinical decision-making regarding treatment options, as well as capacity building on self-management ill health skills. Relevant programs are really scare in Cyprus, mainly provided in private sector. 
Moreover, acute short-term residential treatment programs for dual diagnosis are also proposed to be implemented in Cyprus, aiming to provide simultaneously treatment for mental disturbance symptoms and substance-use related problems ${ }^{69}$. Also, the implementation of compulsory substance use treatment needs to be consider taking into account the cultural context of Cyprus and the data reported herein regarding target populations and duration of programmes.

\section{Limitations}

Data collection took place in a 14 months period which may have jeopardised the generalizability of the present findings. However, since approximately $17 \%$ of the participants were re-admitted in the APH this may suggest that a precise representation of those involuntary admitted for compulsory treatment has been achieved. In other studies, the time period for data collection is mainly 1 to 8 years. More importantly, the cross-sectional design of the present study does not allow any inference in relation the direction of the observed associations. At least with regards to some factors, such as positive history of substance use or family history of mental disorders causality may be assumed. Overall, cross-national comparisons are difficult due to diverse healthcare systems and legislation norms regarding compulsory treatment for mental health problems, however there is a need for collaborative international studies to explore the prevalence of involuntary hospitalization and involuntary re-admissions across different settings and cultures employing common assessment tools and standard methodology. Nevertheless, the large sample in this study, the use of a structured clinical assessment procedure triangulated by two independent researchers permits a accurate data in this population.

\section{Conclusions}

The results of the present study confirm, to a certain degree, previous data regarding clinical and sociodemographic rifk factors for severe relapse leading to involuntary hospitalization for mental health problems. By recording the clinical and socio-demographic characteristics of those under compulsory treatment, a deeper comprehension of their risk profile is achieved within the cultural context of Cyprus. Further studies focusing on the clinical and socio-demographic characteristics of severely mentally ill individuals are proposed in order to develop and implement Clinical Guidelines focused on primary, secondary and tertiary prevention issues. Further studies associating biological markers with clinical and socio-demographic characteristics in clinical populations under compulsory treatment for severe mental health problems are also proposed.

\section{Abbreviations}

APH: Athalassa Psychiatric Hospital; SD: standard deviations; SPSS: Statistical Package for the Social Sciences

\section{Declarations}


Acknowledgments

The research team wishes to thank all participants who contributed.

\section{Funding}

Not applicable.

\section{Availability of data and materials}

The data will not be shared since they refer to sensitive population. Moreover, the participants have signed consent to solely participate in this research study. Also, in accordance to the ethical approval given by the Commissioner of Personal Data Collection, the data must be used only for the current study and access to those data have only the authors/researchers.

\section{Authors' contributions}

Katerina Kaikoushi (KK) conducted the research, participated in data collection, data analysis and drafted the manuscript. Evanthia Bella (EB) participated in data collection. Nicos Middleton in data analysis and in the writing of the manuscript. Andreas Chatzitofi (AC) participated in data analysis and in the writing of the manuscript. Giorgos Alevizopoulos (GA) participated in data analysis and in the writing of the manuscript. Constantinos Stylianou (CS) participated in data collection. Evgenios Kinnis (EK) participated in data collection. Maria Karanikola (MK) paticipated in data analysis and in the writing of the manuscript. Also, MNK was the supervisor of the $\mathrm{PhD}$ work of $\mathrm{KK}$, from which this paper was produced, having contributed equally to the study. All of the authors have read and approved the final manuscript.

\section{Authors' informations}

KK: candidate PhD (Mental Health at Cyprus University of Technology), MSc, BSc, RN, RMHN. EB: M.D., Psychiatrist. NM: PhD, MSc, BSc, is Assistant Professor in Health Research Methodology and Biostatistics in the Department of Nursing, Faculty of Health Sciences, Cyprus University of Technology. Member of the advisory committee of KK at her PhD. GA: M.D., Ph.D., Psychiatrist. Professor and Director of Psychiatry Department of the Oncological Hospital of Kifisia, Athens Greece. National and Kapodistrian University of Athens, Faculty of Nursing. Member of the advisory committee of KK at her PhD. AC: M.D., Ph.D., Psychiatrist, Lecturer, Medical School, University of Cyprus. CS: MD, Psychiatry Res., MSc(c) public health. Cyprus Mental Health Services. KE: MD, Psychiatry Res. Cyprus Mental Health Services. MK: PhD, MSc, BSc, RGN, Assistant Professor in Mental Health Nursing in the Department of Nursing, Faculty of Health Sciences, Cyprus. She has been the PhD supervisor of KK.

\section{Competing interests}

The authors declare that they have no competing interests. 


\section{Consent for publication}

Not applicable.

\section{Ethics approval and consent to participate}

The study protocol was approved by the Cyprus National Bioethics Committee. Approval to gain access to all inpatient mental health services over the island of Cyprus was obtained from the Research Committee of the Ministry of Health of Cyprus, as well as from the Office of the Commissioner of Personal Data Protection. Participants were informed for the purpose and procedure of the study prior to their consensus to participate. All actions were taken to preserve the identity anonymity of the participants and confidentiality according to ethics regarding the collection of data. Furthermore, the participants who met the inclusion criteria read the informative consent form and had the opportunity to ask the researcher further questions before signing. All participants signed an informed consent form. The main researcher had the responsibility of collecting the informed consent forms.

\section{Acknowledgments}

We would like to thank all participants in this study. We would also like to acknowledge the field workers who contributed to the collection of the data.

\section{References}

1. Rehm J, Shield KD: Global Burden of Disease and the Impact of Mental and Addictive Disorders. Current Psychiatry Reports 2019, 21:10-17.

2. Kisely SR, Campbell LA, O'Reilly R: Compulsory community and involuntary outpatient treatment for people with severe mental disorders. Cochrane database of systematic reviews 2017, 3:CD004408. 3. Adebiyi MO, Mosaku SK, Irinoye 00, Oyelade 0: Socio-demographic and clinical factors associated with relapse in mentalillness. International Journal of Africa Nursing Sciences 2018, 8:149-153.

4. Pilarinos A, Barker B, Nosova E, Milloy MJ, Hayashi K, Wood E, et al.: Coercion into addiction treatment and subsequent substance use patterns among people who use illicit drugs in Vancouver, Canada. Addiction 2019, 10:14769.

5. van Kranenburg GD, van den Brink RHS, Mulder WG, Diekman W, Pijnenborg GHM, Mulder CL: Clinical effects and treatment outcomes of long-term compulsory in-patient treatment of treatment-resistant patients with severe mental illness and substance-use disorder. BMC Psychiatry 2019, 19:270-279. 6. Kaite CP, Karanikola M, Merkouris A, Papathanassoglou ED: "An ongoing struggle with the self and illness": a meta-synthesis of the studies of the lived experience of severe mental illness. Archives of Psychiatric Nursing 2015, 29:458-73.

7. Jaeger $S$, Hüther F, Steinert T: Refusing medication therapy in involuntary inpatient treatment-a multiperspective qualitative study. Frontiers in Psychiatry 2019, 10:295-310.

8. Flammer E, Steinert T: Association Between Restriction of Involuntary Medication and Frequency of Coercive Measures and Violent Incidents. Psychiatric Services 2016, 67:1315-1320. 
9. Curley A, Agada E, Emechebe A, Anamdi C, Ng XT, Duffy R, Kelly BD: Exploring and explaining involuntary care: the relationship between psychiatric admission status, gender and other demographic and clinical variables. International Journal of Law and Psychiatry 2016, 47:53-59.

10. Kelly BD, Duffy RM, Curley A: Which involuntary admissions are revoked by mental health tribunals? A report from the Dublin Involuntary Admission Study (DIAS). Psychiatry Research 2018, 262:583-585.

11. Hung YY, Chan HY, Pan YJ: Risk factors for readmission in schizophrenia patients following involuntary admission. PloS One 2017, 12:e0186768.

12. Joint Commission on the Accreditation of Healthcare Organizations. National Patient Safety Goals (http://www.jointcommission.org/patientsafety/nationalpatientsafetygoals) Accessed on date 12/12/2018.

13. Psychiatric Hospitalization Act of 1997 (77 (I)/1997). Cyprus Ministry of Health. Medical and Public Services (https://www.moh.gov.cy/moh/mhs/mhs.nsf/page37_gr/page37_gr?OpenDocument) Assessed on date $15 / 12 / 2018$

14. Cyprus Ministry of Health. Mental health Services of Cyprus Annual Report, 2010 . (https://www.moh.gov.cy/moh/mhs/mhs.nsf/All/5E39356FE0B58FBBC2257AFD003684D9? OpenDocument) Assessed on date 15/12/2018

15. Alexi N, Moore K, Argyrides M: Openness to help-seeking for mental illness among Greek-Cypriots. Health Promotion International 2018, 33:990-998.

16. Golna C, Pashardes P, Allin S, Theodorou M, Mossialos E, Merkur S, World Health Organization: Health care systems in transition: Cyprus. Copenhagen: WHO Regional Office for Europe, 2004.

17. Zacharakis CA, Hadjivassilis V, Madianos MG, Papadimitriou GN, Stefanis CN: Suicide in Cyprus 1988-1999. European Psychiatry 2005, 20:110-114.

18. $\mathrm{Ng} \mathrm{XT,} \mathrm{Kelly} \mathrm{BD:} \mathrm{Voluntary} \mathrm{and} \mathrm{involuntary} \mathrm{care:} \mathrm{three-year} \mathrm{study} \mathrm{of} \mathrm{demographic} \mathrm{and} \mathrm{diagnostic}$ admission statistics at an inner-city adult psychiatry unit. International Journal of Law and Psychiatry 2012, 35:317-326.

19. Wynn R: Involuntary admission in Norwegian adult psychiatric hospitals: a systematic review. International Journal of Mental Health Systems 2018, 12:10.

20. Hawton K, i Comabella CC, Haw C, Saunders K: Risk factors for suicide in individuals with depression: a systematic review. Journal of Affective Disorders 2013, 147:17-28.

21. Rai D, Zitko P, Jones K, Lynch J, Araya R: Country- and individual-level socioeconomic determinants of depression: Multilevel cross-national comparison. British Journal of Psychiatry 2013, 202:195-203.

22. Substance Abuse and Mental Health Services Administration (SASMHSA). Results from the 2010 National Survey on Drug Use and Health: Summary of National Findings, NSDUH Series H-41, HHS Publication No. (SMA) 11-4658. Rockville, MD: Substance Abuse and Mental Health Administration; 2011. 23. Mitsis P: Co-occurring mental illnesses and substance use disorders: Evidence from Cyprus. Archives of Psychiatric Nursing 2019, 33:77-84.

24. Azizi SAA, Omer AA, Mufadel AA: Cannabis use among people with mental illness: Clinical and sociodemographic characteristics. Open Journal of Psychiatry 2018, 8: 244-252.

25. Campolongo P, Trezza V, Cassano T, Gaetani S, Morgese MG, et al.: Perinatal exposure to delta-9tetrahydrocannabinol causes enduring cognitive deficits associated with alteration of cortical gene 
expression and neurotransmission in rats. Addiction biology 2007, 12:485-495.

26. Georgiou N, Karanikola M: (2014) Exploration of the association between cannabis use and the occurrence of early symptoms of psychotic disorders. Nosileftiki 2014, 53:31-44.

27. Munirat OA, Samuel KM, Omolola OI, Oyeyemi OO: Socio-demographic and clinical factors associated with relapse in mental illness. International Journal of Africa Nursing Sciences 2018, 8:149-153.

28. Meehan T, Stedman T, Parker S, Curtis B, Jones D: Comparing clinical and demographic characteristics of people with mental illness in hospital - and community - based residential rehabilitation units in Queensland. Australian Health Review, Journal Compilation 2017, 41:139-143. 29. Potkonjak, J, Karlovic D: Sociodemographic and medical characteristics of involuntary psychiatric inpatients: retrospective study of five-year experience with Croatian Act on Mental Health. Acta Clinica Croatica 2008, 47(3), 141.

30. Tremblay PF, King PR, Baines GR: Clinical and demographic characteristics of voluntary and involuntary psychiatric inpatients. The Canadian Journal of Psychiatry 1994, 39:297-299.

31. Ndukuba AC: Socio-demographic and clinical profile of patients admitted into Ebonyi State University Teaching Hospital: a three-year retrospective study. Ebonyi Medical Journal 2011, 10:47-55.

32. Kieber-Ospelt I, Theodoridou A, Hoff P, KawohI W, Seifritz E, Jaeger M: Quality criteria of involuntary psychiatric admissions-before and after the revision of the civil code in Switzerland. BMC Psychiatry 2016, 16:291-301.

33. Papageorgiou A, King M, Janmohamed A, Davidson O, Dawson J: Advance directives for patients compulsorily admitted to hospital with serious mental illness: randomised controlled trial. British Journal of Psychiatry 2002, 181:513-519.

34. Tørrissen T: Involuntary admissions to an acute psychiatric ward. Tidsskrift for den Norske laegeforening: tidsskrift for praktisk medicin, ny raekke 2007, 127:2086-2089.

35. Wierdsma Al, Mulder CL: Does mental health service integration affect compulsory admissions?. International Journal of Integrated Care 2009, 9:1-8.

36. Szmukler GI, Bird AS, Button EJ: Compulsory admissions in a London borough: I. Social and clinical features and a follow-up. Psychological Medicine 1981, 11:617-636.

37. Hotzy F, Hengartner MP, Hoff, Jaeger M, Theodoridou A: Clinical and socio-demographic characteristics associated with involuntary admissions in Switzerland between 2008 and 2016: An observational cohort study before and after implementation of the new legislation. European Psychiatry 2019, 59:70-76.

38. Skokou M, Gouma P, Gourzis P: Compulsory admissions in southwest Greece 2010-2011: A descriptive report. Psychiatriki 2017, 28:265-273.

39. Julius RJ, Novitsky Jr MA, Dubin WR: Medication adherence: a review of the literature and implications for clinical practice. Journal of Psychiatric Practice 2009, 15:34-44.

40. Velligan DI, Weiden PJ, Sajatovic M, Scott J, Carpenter D, Ross R, Docherty JP: The Expert Consensus Guideline Series: Adherence problems in patients with serious and persistent mental illness. Journal of Clinical Psychiatry 2009, 70 (Suppl. 4):1-46.

41. Aguglia A, Moncalvo M, Solia F, Maina G: Involuntary admissions in Italy: the impact of seasonality. International journal of psychiatry in clinical practice 2016, 20:232-238. 
42. Gültekin BK, Çelik S, Tihan A, Beşkardeş AF, Sezer U: Sociodemographic and clinical characteristics of psychiatric inpatients hospitalized involuntarily and voluntarily in a mental health hospital. Nöro Psikiyatri Arşivi 2013, 50:216-221.

43. Geniş B, Coşar B, Candansayar S, Gürhan, N: Voluntary/Involuntary Admissions/Readmissions of Psychiatric Patients in a University Hospital in Turkey From 2008 to 2016. Hospital Practices and Research 2018, 3:123-129.

44. Lebenbaum M, Chiu M, Vigod S, Kurdyak P: Prevalence and predictors of involuntary psychiatric hospital admissions in Ontario, Canada: a population-based linked administrative database study. BJPsych open 2018, 4:31-38.

45. Priebe S, Katsakou C, Yeeles K, Amos T, Morriss R, Wang D, Wykes T: Predictors of clinical and social outcomes following involuntary hospital admission: a prospective observational study. European archives of psychiatry and clinical neuroscience 2011, 261:377-386.

46. Silva B, Golay P, Morandi S: Factors associated with involuntary hospitalisation for psychiatric patients in Switzerland: a retrospective study. BMC psychiatry 2018, 18:401-411.

47. Stylianidis S, Peppou LE, Drakonakis N, Douzenis A, Panagou A, Tsikou K et al.: Mental health care in Athens: are compulsory admissions in Greece a one-way road?. International Journal of Law and Psychiatry 2017, 52:28-34.

48. Hakim M, Airin J, Naher S, Ali M, Ahmad M, Al-Azad M: Socio-demographic characteristics of mentally ill patients admitted to different hospitals of Dhaka city. JAFMC Bangladesh 2014, 10:44-49.

49. Amoran OE, Lawoyin TT, Oni OO: Risk factors associated with mental illness in Oyo State, Nigeria: A community based study. Annals of General Psychiatry 2005, 4:1-6.

50. Douzenis A, Michopoulos I, Economou M, Rizos E, Christodoulou C, Lykouras L: Involuntary admission in Greece: A prospective national study of police involvement and client characteristics affecting emergency assessment. International Journal of Social Psychiatry 2012, 58:172-177.

51. Hustoft K, Larsen TK, Auestad B, Joa I, Johannessen JO, Ruud T: Predictors of involuntary hospitalizations to acute psychiatry. International Journal of Law and Psychiatry 2013, 36:136-143. 52. Chang TMM, Ferreira LK, Ferreira MP, Hirata ES: Clinical and demographic differences between voluntary and involuntary psychiatric admissions in a university hospital in Brazil. Cadernos de Saude Publica 2013, 29:2347-2352.

53. Gou L, Zhou JS, Xiang YT, Zhu XM, Correll CU, Ungvari GS, et al.: Frequency of involuntary admissions and its associations with demographic and clinical characteristics in China. Archives of Psychiatric Nursing 2014, 28:272-276.

54. World Health Organization Mental health action plan 2013-2020. Geneva, Switzerland: WHO Document Production Services, 2013

(https://www.who.int/mental_health/publications/action_plan/en/) Assessed 21/12/2018

55. van der Post LF, Peen J, Visch I, Mulder CL, Beekman AT, Dekker JJ: Patient perspectives and the risk of compulsory admission: the Amsterdam Study of Acute Psychiatry V. International Journal of Social Psychiatry 2014, 60:125-133.

56. Craw J, Compton MT: Characteristics associated with involuntary versus voluntary legal status at admission and discharge among psychiatric inpatients. Social Psychiatry and Psychiatric Epidemiology 
2016, 41:981-988.

57. Armanmehr V, Shaghgasemi Z, Alami A, Moradi N, Rezaeian S: Poor mental health status and its related socio-demographic factors: A population-based cross-sectional study. Epidemiology Biostatistics and Public Health 2016, 13:e11662-1-e11662-7.

58. Kern RS, Zarate R, Glynn SM, Turner LR, Smith KM, Mitchell SS, et al.: A demonstration project involving peers as providers of evidence-based, supported employment services. Psychiatric rehabilitation journal 2013, 36: 99-107.

59. Dreger S, Buck C, Bolte G: Material, psychosocial and sociodemographic determinants are associated with positive mental health in Europe: a cross-sectional study. BMJ open 2014, 4:e005095.

60. Ndetei DM, Khasakhala L, Maru H, Pizzo M, Mutiso V, Ongecha-Owuor FA, Kokonya DA: Clinical epidemiology in patients admitted at Mathari

Psychiatric Hospital, Nairobi, Kenya. Social Psychiatry and Psychiatric Epidemiology 2008, 43:736-742.

61. Kelemen O, Kiss I, Benedek G, Keri S: Perceptual and cognitive effects of antipsychotics in firstepisode schizophrenia: the potential impact of GABA concentration in the visual cortex. Prog.

Neuropsychopharmacology Biology Psychiatry 2013, 47:13-19.

62. Kiss I, Fabian A, Benedek G, Keri S: When doors of perception open: visual contrast sensitivity in nevermedicated, first-episode schizophrenia. Journal of Abnormal Psychology 2010, 119:586-593.

63. Chapman J: The early symptoms of schizophrenia. British Journal of Psychiatry 1996, 12:225-251

64. Vollmer-Larsen A, Handest P, Parnas J: Reliability of measuring anomalous experience: the Bonn Scale for the Assessment of Basic Symptoms. Psychopathology 2007, 40:345-348.

65. Shuwairi SM, Cronin-Golomb A, Mccarley RW, O'donnell BF: Color discrimination in schizophrenia. Schizophrenia Research 2002, 55:197-204.

66. Almeida T, Molodynski A: Compulsory admission and involuntary treatment in Portugal. BJPsych International 2016, 13:17-19.

67. Caldas de Almeida JM: Portuguese National Mental

Health Plan (2007-2016) executive summary. Mental Health in

Family Medicine 2019, 6:233-244

68. Preston NJ, Kisely S, Xiao J: Assessing the outcome of compulsory psychiatric treatment in the community: epidemiological study in Western Australia. Bmj Journals 2002, 324:1244-1249.

69. Brunette MF, Drake RE, Woods M, Hartnett T: A comparison of long-term and short-term residential treatment programs for dual diagnosis patients. Psychiatric Services 2001, 52:526-528.

\section{Tables}


Table I. Socio-Demographic and Clinical Characteristics of adults under involuntary hospitalization in Cyprus

\begin{tabular}{|c|c|c|}
\hline Variables & $\begin{array}{c}\text { Frequency } \\
(n=406)\end{array}$ & $\%$ \\
\hline \multicolumn{3}{|l|}{ Gender } \\
\hline Male & 262 & 64,5 \\
\hline Female & 144 & 35,5 \\
\hline \multicolumn{3}{|l|}{ Age Group } \\
\hline $18-24$ & 53 & 13,0 \\
\hline $25-34$ & 129 & 31,8 \\
\hline $35-44$ & 90 & 22,2 \\
\hline $45-65$ & 134 & 33,0 \\
\hline \multicolumn{3}{|l|}{ Admission Frequency } \\
\hline First Admission & 195 & 48,0 \\
\hline Readmission & 211 & 52,0 \\
\hline \multicolumn{3}{|l|}{ Episode No. } \\
\hline $1^{\text {st }}$ Episode & 118 & 29,1 \\
\hline Positive Previous History & 288 & 70,9 \\
\hline \multicolumn{3}{|l|}{ Admission Era } \\
\hline Winter & 130 & 32,0 \\
\hline Spring & 87 & 21,4 \\
\hline Summer & 97 & 29,3 \\
\hline Autumn & 92 & 22,7 \\
\hline \multicolumn{3}{|l|}{ Ethnicity } \\
\hline Cypriot & 294 & 72,4 \\
\hline Other & 110 & 27,6 \\
\hline \multicolumn{3}{|l|}{ Race } \\
\hline White & 372 & 91,6 \\
\hline Other & 34 & 8,4 \\
\hline \multicolumn{3}{|l|}{ Language } \\
\hline Greek & 333 & 82,0 \\
\hline Other & 73 & 18,0 \\
\hline
\end{tabular}


Christian Orthodox

Other

Residence

Nicosia

Limassol

Larnaca

Paphos

Famagusta

Marital Status

Unmarried

Married

Educational Status

University

Secondary

Primary

Professional Status

Employee

Unemployed

Financial Allowance

Yes

No

Eye Color

Black

Brown

Blue

Green

Hair Color

Brown

Black

Blond

Red

$B M I$
330

81,3

76

18,7

156

38,4

109

26,8

78

19,2

41

10,1

22

5,4

350

85,7

66

14,3

101

24,9

162

39,9

142

35,2

91

22,4

315

77,6

201

49,5

205

50,5

225

55,4

138

34,0

38

9,4

4

1,0

1,0

66

16,3

275

67,7

41

10,1

23

5,7 
Low Weight $\left(<18,5 \mathrm{~kg} / \mathrm{m}^{2}\right)$

Normal $\left(18,5-25 \mathrm{~kg} / \mathrm{m}^{2}\right)$

Overweight $\left(25-305 \mathrm{~kg} / \mathrm{m}^{2}\right)$

Obese $\left(>305 \mathrm{~kg} / \mathrm{m}^{2}\right)$

Substance Abuse

Yes

No

Family History

Positive

Negative

Unknown

Diagnosis

Schizophrenia

Relevant Psychotic Disorders

Mood Disorders

Other

Admission Symptoms

Medication Non-Adherence \& Lack of Insight

Substance Abuse \& Lack of Insight

Self-harm/ Suicidal Behaviour

Aggressive Behaviour Against Others

Lack of Insight
18

4,4

191

47

104

25,6

53

13,1

172

234

42,4

57,6

$\begin{array}{rr}171 & 42,1 \\ 177 & 43,6 \\ 58 & 14,3\end{array}$

31

7,6

320

78,8

48

11,8

7

1,7

$7 \quad 1,7$

232

57,1

34

8,4

6

1,5

39

9,6

95

23,4 
Table II. Substance Use

Characteristics (Frequency, Type of Use, Dual Diagnosis)

\begin{tabular}{lrr}
\hline Variables & $\begin{array}{c}\text { Frequency } \\
(n=172)\end{array}$ & \multicolumn{1}{l}{$\%$} \\
\hline Frequency of Use & 90 & 52,3 \\
\hline Daily & 71 & 41,3 \\
\hline Occasionally & 11 & 6,4 \\
\hline Other & & \\
\hline Type of Use & 130 & 75,6 \\
$\quad$ Cannabis & 27 & 15,7 \\
\hline Alcohol & 15 & 8,7 \\
$\quad$ Other & & \\
\hline Dual Diagnosis & 117 & 69,0 \\
\hline Yes & 55 & 31,0 \\
$\quad$ No & & \\
\hline Multiuse & 82 & 47,7 \\
\hline Yes & 90 & 52,3 \\
$\quad$ No & & \\
&
\end{tabular}

Table III. Family History Diagnosis $(\mathrm{N}=171)$

\begin{tabular}{lrr} 
Schizophrenia or Relevant Psychotic Disorder & 73 & 41,7 \\
\hline Mood Disorder & 52 & 30,4 \\
\hline Substance Abuse & 6 & 3,5 \\
\hline Schizophrenia or Rel. Psychotic Dis. \&Substance Abuse & 4 & 2,3 \\
\hline Mood Disorder \& Substance Abuse & 5 & 2,9 \\
\hline Schizophrenia or Rel. Psychotic Dis.\&Mood Disorder & 16 & 9,3 \\
\hline Other & 17 & 9,9
\end{tabular}

\section{Figures}




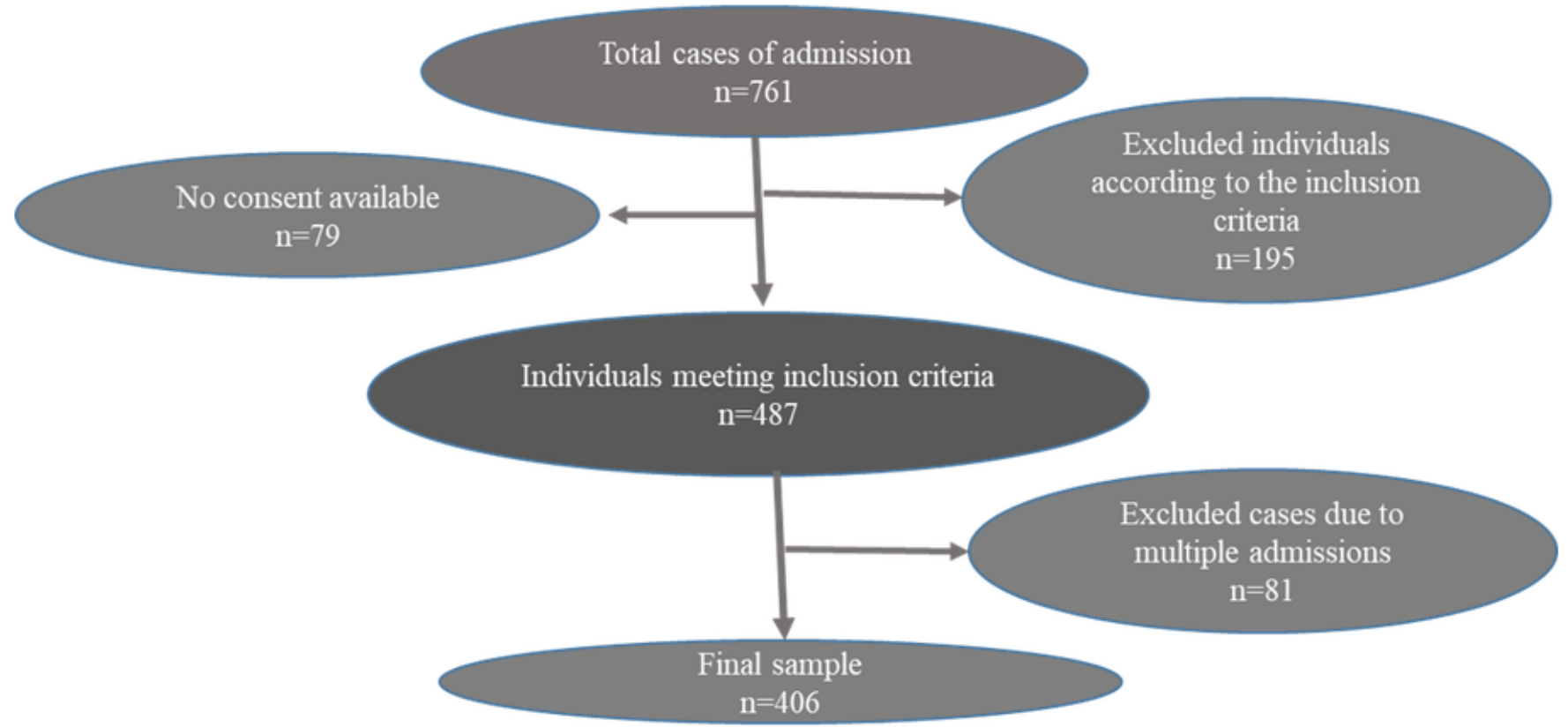

Figure 1

Flowchart of the final sample which consisted of 406 individuals. 